ISSN: 2162-3104 Print/ ISSN: 2166-3750 Online Volume 8, Number 1, January/February (2018) pp. I-III (C) Journal of International Students http://jistudents.org/

\title{
Exposed Challenges, Emerging Opportunities
}

\author{
Krishna Bista \\ Morgan State University, United States
}

\begin{abstract}
"This is a critical time for scholars who study international students to reassess our research agenda for the field," remarked Rose-Redwood and Rose-Redwood (2017) in their guest editorial here two issues ago, "because we simply cannot proceed as if it were business as usual within the current political context" (p. ii). Addressing the rise of anti-immigrant environment in the country more generally, Glass (2017) wrote in the preceding editorial that "[a] staunch acceptance of reality must be buttressed by strongly held values," enumerating values such as "promoting global engagement and understanding, engaging in civic responsibility beyond local contexts, fostering the appreciation for languages and cultures, and strengthening foreign relations and peace building among nations" (p. ii). The politics and policy about international students in the United States has not moved in any better directions since last year. From many and confusing attempts at travel restrictions to deleterious impacts of hostile policies about undocumented students, and from stricter visa regulations about international students to proposed dramatic changes about all immigrants, international students are facing the effects of increasingly adverse politics and policy, directly and indirectly. As Rose-Redwood and Rose-Redwood went on to say, "[i]n contexts where xenophobia, racism, and religious hatred are prevalent. ... physical and symbolic violence as well as implicit and explicit discrimination. . . . fall along a continuum, ranging from everyday forms of microaggression to violent hate crimes" (p. v). They proposed that future research on international students and education focus on policy environments, sociopolitical atmosphere, the continuum of violence and discrimination, student activism and resistance, and careful deliberation about the positionality of researcher.

On the global level, mobility of international students is increasingly in flux, and news reports indicate rising tensions and more and
\end{abstract}


more unsafe environment for international students. Both local and transnational realities demand that our research and scholarship transcend conventional frameworks, disciplinary boundaries, and apolitical framing. We need broader, bolder visions. In particular, we must pursue our scholarship with the understanding that international students are not just a product of the modern "market," nor, indeed, should they be seen as the byproduct of nation formation. Before there was the current idea of the market of international education and even before nations became the most dominant unit of social organization, people moved to new places to broaden their knowledge and enrich their experience, to exchange ideas between home and host communities, to make sense of life and society. If need (or greed) for food and space led to border-crossing that involved conflicts, mobility driven by curiosity and exchange of ideas has historically mitigated ignorance, fear, and violence--rather than magnify or facilitate it. Unfortunately, in modern times, regulation of bodies, then of knowledge and its exchange, by nation states (which have somehow come to be defined by conflict and competition) are increasingly clashing against common humanistic goals among nations, against globalization and against the advancement of knowledge in the interest of all. In fact, education has often been used to brainwash and intimidate, regulate and restrict the freedom of bodies and minds.

What we see today is a puzzling mix of the use and abuse of opportunities that mobility of the learned and learners can offer. In this context, educators must question whether the nationalistic foundation (Marginson, 2013) of today's international education, and indeed national education is sufficient. We must advance international higher education as a means of global social mobility, or the upward movement of people across national borders by their social class. We must also advocate for what Marginson calls "quasi national status" for students while they are not in their home countries; they deserve full freedom, rights, and opportunities to thrive as individuals, wherever they may be citizens of. Within nationalistic worldviews that are further shaped by ethnic/racial definitions of nationhood/citizenship, international students are not neighbors who have come over to learn, our neighbors' children whose wellbeing we are responsible toward. They are just "others" whose value is seen in their financial contribution (and sometimes cultural, educational backgrounds). What extremist political ideology does is to take the lid off longstanding beliefs and assumptions that were deemed norm(al) and that used to shape mainstream policy and academic discourse and practice. Bigotry and xenophobia, in this sense, expose blatant or visible/audible forms of prejudice and bias that are embedded within formal policies and everyday discourse. It is imperative today for scholars to turn our attention to this reality. 
As this journal strives to cover issues pertaining to tectonic shifts in the political and policy environments, this issue includes a variety of articles in which authors continue to collectively demonstrate the vibrancy of scholarly conversations on international students: health experiences, measures of student success, interculturality, cultural competency, and job search and employment for international students, acculturative stress and sociocultural adaptation, academic adaptation, cultural orientation, student engagement and sense of belonging, university life, students meal preference, and student learning styles. In this volume, 60 authors, who represented several institutions of higher education, have shared their perspectives and research findings (both quantitative and qualitative) based on their experiences in Australia, China, Malaysia, Norway, India, the United Kingdom, and the United States. Each article is rich in term of cross cultural perspectives of mobile students, their learning experiences, and campus diversity.

Altogether, we believe that scholarly articles of this volume from various disciplines will contribute positively to the field of international student studies. As in the past, we have continued our tradition of sharing free digital copies with students, faculty members and libraries in the United States and abroad. Finally, I would like to thank the reviewers, copy editors, assistant editors, editors, and our advisory board members for their voluntary contributions to the journal

Happy reading!

\section{References}

Glass, C. R. (2017). Resilience for a world in flux. Journal of International Students, 7(2), I-IV.

Marginson, S. (2013). Equals or others? Mobile students in a nationally bordered world. In Sovic, S., \& Blythman, M. International students negotiating higher education: Critical perspectives (pp. 9-27). New York, NY: Routledge.

Rose-Redwood, C., \& Rose-Redwood, R. (2017). Rethinking the politics of international student experience in the age of Trump. Journal of International Students, 7(3), I-IX. doi: 10.5281/zenodo.569939. 